\title{
PERANCANGAN SISTEM MANAJEMEN GUDANG MATERIAL PENUNJANG DI PT XYZ
}

\author{
Benedictus Rahardjo* \\ Fakultas Teknologi Industri, Program Studi Teknik Industri, Universitas Kristen Petra. Jl. Siwalankerto 121-131, Surabaya \\ 60236.
}

(Received: February 7, 2017 / Accepted: July 17, 2017)

\begin{abstract}
Abstrak
Studi ini membahas tentang pembuatan sistem dan standar untuk mengontrol sistem gudang agar memudahkan pencarian material dan pengontrolan gudang. Gudang material penuh dan susahnya pencarian material dikarenakan tidak adanya prosedur yang mengatur bagaimana seharusnya gudang tersebut beroperasi. Penelitian ini menggunakan metode pengamatan langsung di lapangan serta tanya jawab terhadap pihak-pihak yang berhubungan dengan gudang material. Hasil dari pengamatan kemudian disusun menjadi sistem manajemen baru dalam bentuk Standard Operating Procedure (SOP), aturan-aturan, serta tata letak material baru. Berdasarkan SOP yang ada kemudian dibuatlah kartu stok dan table material induk sebagai alat controling pada gudang. Controling dilakukan dengan tujuan agar gudang berjalan sesuai SOP yang ada dan tidak kembali pada permasalahan yang lama.
\end{abstract}

Kata Kunci : Sistem Manajemen Gudang, SOP, Layout.

\begin{abstract}
This study has been done to create a system and standard to control the warehouse system for ease finding tools and control the warehouse. The warehouse is full and finding tools is hard because there is no regulation to control how the warehouse should be running. This project uses direct observation in the field and Q\&A against the department which have relation with supporting tools warehouse. The results of the observations then organized into a new management system in form of Standard Operating Procedure (SOP), rules, and new layout for tools. Based on existing SOP, stock card and parent material table is made as for controlling tool for the warehouse. Controlling is done with the aim that the warehouse goes according to SOP and did not return to the old problems.
\end{abstract}

Keywords : Warehouse Management System, SOP, Layout.

\section{Pendahuluan}

PT XYZ merupakan perusahaan yang bergerak dalam bidang jasa offset printing, mulai untuk produk dari etiket, label, sampai dengan beraneka ragam kemasan yang terbuat dari duplex carton box. Bermacam-macam produk yang diproduksi menjadikan PT XYZ membutuhkan penanganan gudang yang baik. Gudang merupakan bagian yang penting dari suatu proses produksi, dikarenakan gudang merupakan tempat penyimpanan material produksi. Manajemen gudang sangat diperlukan agar aliran rantai pasok dapat berjalan dengan baik. Tata letak juga memegang peranan penting dan memiliki banyak dampak strategis bagi perusahaan. Tata letak mempengaruhi perusahaan dari segi kapasitas, aliran material, fleksibilitas, biaya, kualitas lingkungan kerja, dan lain sebagainya. PT XYZ sedang mengembangkan gudang untuk material penunjang yang dibutuhkan ketika melakukan

\footnotetext{
*) Penulis Korespondensi.

Email : beni@petra.ac.id
}

proses produksi. Gudang material lama akan dibuat menjadi Gudang Material Penunjang yang dikembangkan dan bertujuan untuk mempermudah dan memperlancar proses produksi. Gudang Material Penunjang ini berisi material yang dibutuhkan mesin ketika beroperasi, maupun acuan warna dalam produksi. Material ini mempunyai masa hidup (shelf life), karena itu harus tersedia ketika akan produksi. Gudang Material Penunjang ini juga diharuskan dapat menangani dan mengatur material yang dibutuhkan untuk produksi, tidak seperti gudang material lama yang bersifat hanya sebagai tempat peletakan barang selesai pakai tanpa pengontrolan material di dalamnya. Gudang Material Penunjang diharapkan mempunyai suatu sistem yang dapat memperlancar keluar masuknya barang dan dapat dicari dengan mudah. Untuk itulah tata letak penempatan barang dalam Gudang Material Penunjang perlu diatur dengan baik. Pelabelan barang dalam Gudang Material Penunjang juga harus benar dan mudah untuk menemukan barang yang dicari. 


\section{Metode Penelitian}

Pada bagian ini akan dibahas metode-metode yang akan digunakan untuk menyelesaikan permasalahan dalam penelitian ini.

\section{Sistem Manajemen Gudang}

Gwynne Richards (2011) mendefinisikan gudang sebagai fasilitas khusus yang bersifat tetap, yang dirancang untuk mencapai target tingkat pelayanan dengan total biaya yang paling rendah. Manajemen pergudangan dirancang bertujuan untuk mengontrol kegiatan pergudangan yang diharapkan dari pengontrolan ini adalah terjadinya pengurangan biaya-biaya yang ada di dalam gudang, pengambilan dan pemasukan barang ke gudang yang efektif dan efisien, serta kemudahan dan keakuratan informasi stok barang di gudang.

\section{Fixed Location System}

Menurut Arnold (2008) fixed location system adalah sistem penempatan barang pada lokasi yang telah ditentukan sebelumnya dan tidak dapat dicampur dengan barang-barang yang berbeda jenis dari yang telah ditentukan. Barang yang disimpan kelihatan rapi dan gampang ditemukan. Metode ini biasanya dipakai oleh gudang kecil yang tidak terlalu menyimpan banyak barang di dalamnya.

\section{Floating Location System}

Menurut Arnold (2008) floating location system adalah sistem yang membuat penempatan barang pada gudang dapat diletakkan pada lokasi yang berbeda-beda. Tidak adanya penentuan tempat dalam peletakan barang membuat penggunaan tempat yang ada tersedia menjadi lebih efisien. Barang pada gudang dapat diletakkan dimana saja, yang penting ter-update lokasinya pada sistem.

\section{Standard Operating Procedure (SOP)}

Sebuah prosedur operasi yang standar atau biasa disingkat SOP sangatlah dibutuhkan dalam dunia industri. SOP yang sudah dibentuk haruslah diteliti dan dibandingkan dengan keadaan sesungguhnya di lapangan, guna memastikan semua kegiatan berjalan sesuai standar (Tompkins and Smith, 1998).

SOP tidaklah harus dalam bentuk dokumen. Salah satu contoh SOP selain dokumen yaitu bulletin form, seperti dibahas oleh Rahardjo dan Rahardjo (2013). Dalam penelitiannya, mereka menyatakan bahwa bulletin form dapat digunakan sebagai SOP bagi operator mesin yang mengoperasikan mesin setiap harinya. Dengan begitu, peningkatan yield yang telah dicapai dapat stabil dan memiliki kecenderungan untuk meningkat.

\section{Perbaikan Tata Letak Gudang}

Tata letak gudang sangatlah penting untuk diperhatikan, karena dapat berhubungan langsung dengan lamanya waktu penyelesaian aktivitas dan kesalahan stok. Hapsari et.al. (2011) membuktikan betapa pentingnya perbaikan tata letak gudang, karena pada kondisi awalnya produk sulit untuk dicari, karena belum adanya penataan untuk penempatan produk dan pengaturan alokasi space. Oleh sebab itu, diperlukan penataan gudang yang memperhatikan tingkat turn over dan sifat dari masing-masing kelompok jenis produk, serta space yang tersedia.

Irawan (2014) menunjukkan bahwa permasalahan yang terjadi dikarenakan SOP tidak dijalankan dengan baik. Leopatria dan Palit (2013) menyatakan bahwa rancangan perhitungan dan perbaikan nota-nota yang dibuat dapat menyelesaikan permasalahan yang ada pada gudang.

\section{Hasil dan Pembahasan}

Pembuatan rancangan sistem manajemen Gudang Material Penunjang dilakukan untuk mengatur gudang material yang ada saat ini. Pembuatan job description staf, SOP, instruksi kerja, peraturan, maupun tata letak penempatan material merupakan rancangan sistem manajemen Gudang Material Penunjang.

PT XYZ memiliki berbagai macam produk dan membutuhkan berbagai macam material penunjang yang berbeda-beda untuk setiap produknya.

\section{Material pada Gudang}

Material penunjang yang dibutuhkan untuk proses produksi secara umum terdiri dari 7 jenis yaitu pisau plong, dieline, map approval, contoh cetakan, klise emboss/ hotstamp, plate, dan polymer. Map approval, contoh cetakan, dan dieline akan diletakkan pada map besar, sedangkan polymer akan diletakkan pada dus-nya. Jenis material dan dimensinya yang akan disimpan pada Gudang Material Penunjang dapat dilihat pada Tabel 1. Material pada gudang mempunyai masa hidup (shelf life) dan harus dikontrol agar tidak membuat gudang menjadi penuh.

Tabel 1. Jenis dan Dimensi Material

\begin{tabular}{lccc}
\multicolumn{1}{c}{$\begin{array}{c}\text { Jenis } \\
\text { Material }\end{array}$} & $\begin{array}{c}\text { Panjang } \\
(\mathbf{c m})\end{array}$ & $\begin{array}{c}\text { Lebar } \\
(\mathbf{c m})\end{array}$ & $\begin{array}{c}\text { Tinggi } \\
(\mathbf{c m})\end{array}$ \\
\hline $\begin{array}{l}\text { Plate } \\
\text { Pisau } \\
\text { plong }\end{array}$ & 113 & 0.2 & 93 \\
$\begin{array}{l}\text { Klise } \\
\text { Emboss }\end{array}$ & 115 & 3 & 83 \\
$\begin{array}{l}\text { Dus } \\
\text { Polymer }\end{array}$ & 15 & 0.5 & 7 \\
Map Besar & 113 & 5 & 83 \\
\hline & & 2 & 88
\end{tabular}

\section{Kondisi Awal Gudang Material}

Gudang material awal terbagi menjadi 2 lokasi penyimpanan yaitu gudang pisau yang menyimpan pisau plong dan gudang dieline yang menyimpan dieline, map approval, dan contoh cetakan. Material lain ada yang diletakkan pada lantai produksi, tempat pembuatan pisau, maupun sepanjang jalan menuju produksi.

\section{Sistem Awal Gudang Material}

Pada gudang pisau terdapat 1 staf yang membantu penyimpanan dan pengeluaran pisau plong. Pada gudang dieline juga terdapat 1 staf yang mengeluarkan dan menyimpan dieline, contoh cetakan, dan map approval. Pada kedua gudang tidak terdapat sistem pencatatan keluar masuk material. Berikut sistem gudang material pada PT XYZ:

- Penerimaan barang 
Penerimaan material dilakukan pada saat material yang baru selesai dibuat/ dibeli dan ketika bagian produksi selesai memakai material tersebut maka akan dikembalikan kepada staf gudang.

- Penyimpanan barang

Material yang baru dibuat/ dibeli akan disimpan dahulu pada gudang sampai ketika dibutuhkan oleh produksi. Material yang telah selesai dipakai juga akan disimpan oleh staf gudang.

- Pengeluaran barang

Staf gudang mengeluarkan material dan mengantarkannya ke bagian produksi yang memakai material tersebut ketika ada permintaan.

\section{Permasalahan pada Gudang Material}

Dari pengamatan, wawancara, dan informasi yang didapatkan, ada beberapa permasalahan pada gudang material yang sekarang. Gudang pisau yang penuh dan pencarian material yang susah setiap kali dibutuhkan merupakan permasalahan pada gudang material sekarang. Permasalahan yang ada pada gudang material harus diselesaikan sampai pada akar permasalahannya. Hal ini dilakukan agar masalah awal tidak kembali lagi dan membuat penyelesaian masalah menjadi sia-sia. Alat fishbone diagram dapat digunakan untuk membantu mencari akar permasalahan yang ada dan menyelesaikan permasalahan sampai akarnya.

Berdasarkan hasil pengamatan dan wawancara, melalui alat fishbone diagram, pada akhirnya akar-akar permasalahan digolongkan ke dalam sisi man dan method saja, dikarenakan kedua faktor tersebutlah yang paling berpengaruh menyebabkan masalah terjadi. Fishbone diagram untuk mencari akar permasalahan dapat dilihat pada Gambar 1 dan Gambar 2.

Gambar 1 menjelaskan akar permasalahan dari penyebabpenyebab yang membuat gudang penuh. Sebagian besar akar permasalahan dari permasalahan gudang penuh adalah karena disebabkan tidak adanya aturan yang dibuat untuk mengatur gudang material. Dari sisi "man" staf gudang material tidak berfungsi sebagai pengontrol material, tetapi lebih ke arah persiapan material untuk produksi. Material untuk produkproduk lama banyak yang tidak terpakai dan tidak dikeluarkan dari gudang membuat tumpukan material semakin banyak. Staf gudang tidak ada yang mempunyai inisiatif untuk melakukan perubahan atau perbaikan pada gudang materialnya.

Gambar 2 menjelaskan akar permasalahan dari sisi "man" yang membuat pencarian material susah pada gudang material adalah karena staf bergantian setiap shift-nya menyebabkan buruknya informasi soal penempatan material yang keluar masuk pada gudang selama jam kerja shift-nya ketika berganti shift. Staf tidak saling menginformasikan untuk peletakan material yang masuk keluar, hanya memberi tahu bahwa material apa saja yang masuk dan keluar. Label yang tidak jelas dikarenakan penamaan material oleh staf gudang sering disingkat juga membuat pencarian akan material yang dibutuhkan semakin susah.

Dari sisi "method" yang menjadi akar masalahnya adalah tidak adanya aturan yang jelas mengenai bagaimana penataan material pada rak, tidak ada perintah atau aturan untuk mencatat material keluar masuk, dan tidak ada aturan mengenai kejelasan stok opname. Tidak berjalannya inspeksi/ stok opname juga membuat material semakin banyak dan membuat pencarian material bertambah susah.

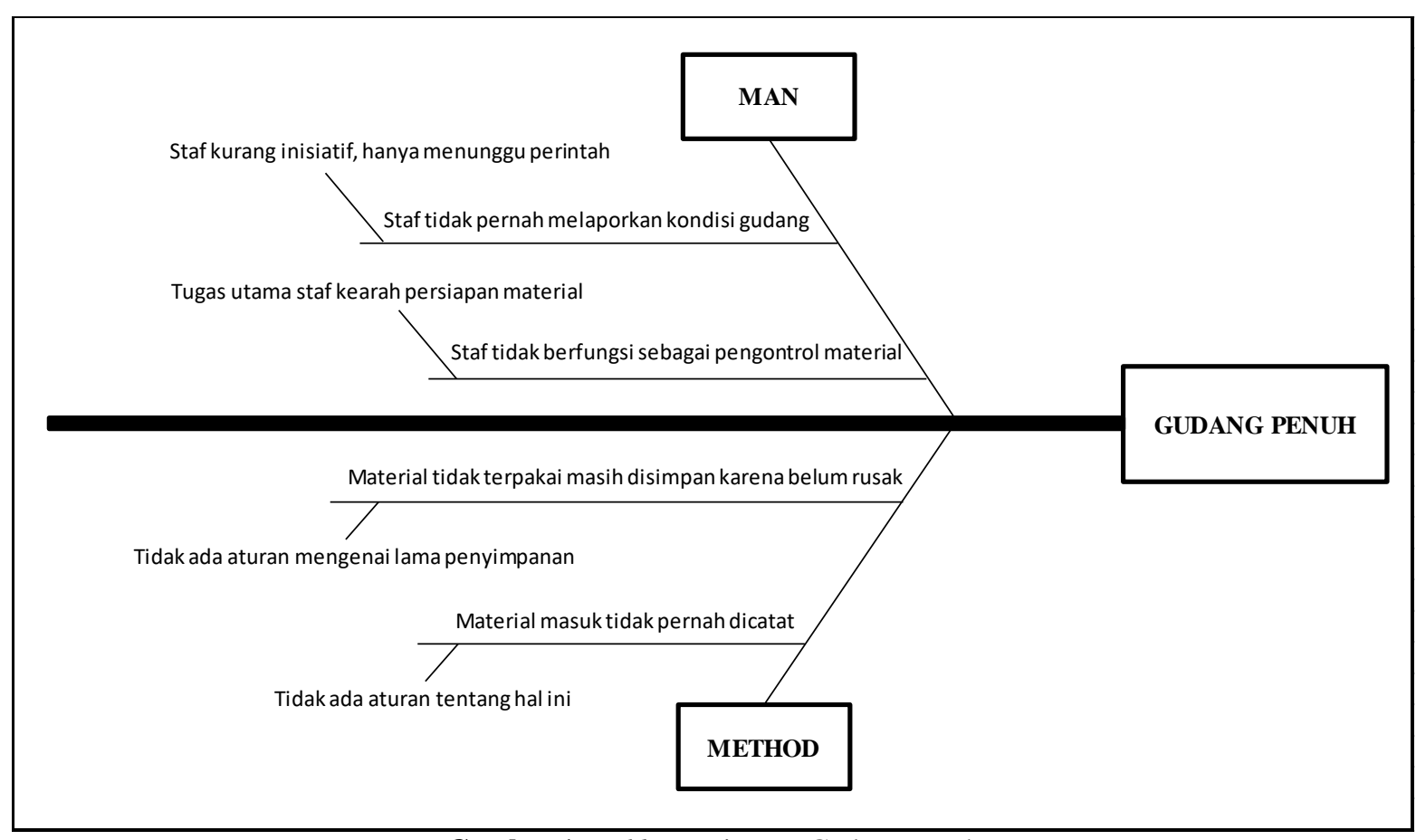

Gambar 1. Fishbone Diagram Gudang Penuh 


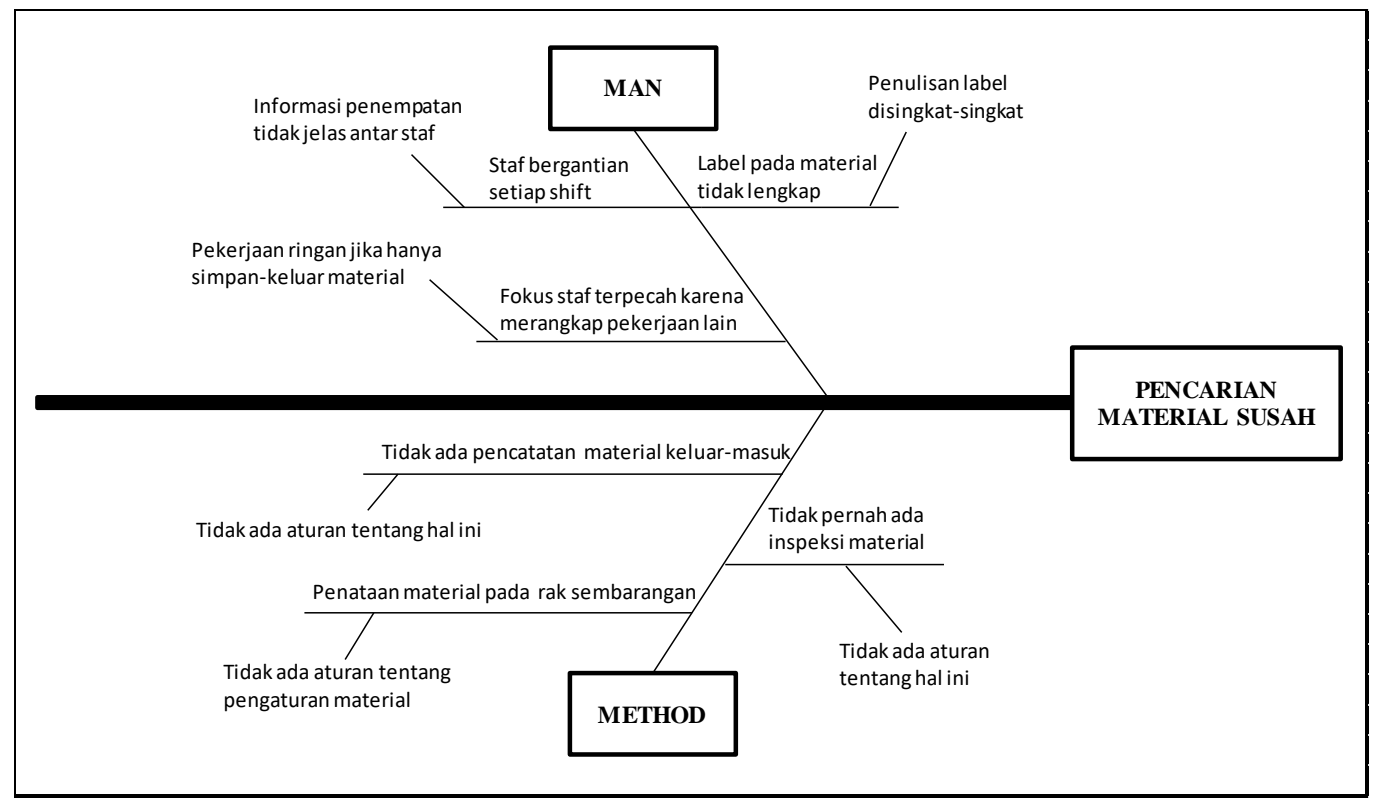

Gambar 2. Fishbone Diagram Pencarian Material Susah

Tabel 2. Job Description Staf

\begin{tabular}{|c|c|}
\hline $\begin{array}{l}\text { JABATAN } \\
\text { DEPARTEMEN } \\
\text { DIVISI } \\
\text { LOKASI }\end{array}$ & $\begin{array}{ll}: & \text { STAF GUDANG MATERIAL PENUNJANG } \\
: & \text { PPIC } \\
: & \text { SUPPLY CHAIN } \\
: & \text { SEPANJANG } \\
\end{array}$ \\
\hline \multicolumn{2}{|c|}{ FUNGSI JABATAN } \\
\hline \multicolumn{2}{|c|}{$\begin{array}{l}\text { Mengendalikan dan mengontrol ketersediaan semua material penunjang yang diperlukan di proses produksi (Offset-Finishing 1) } \\
\text { untuk memastikan kelancaran proses produksi sebuah job. }\end{array}$} \\
\hline \multicolumn{2}{|c|}{ TANGGUNG JAWAB UTAMA } \\
\hline $\mathrm{Me}$ & Mengatur dan mengontrol material penunjang yang dibutuhkan untuk proses produksi. \\
\hline $\mathrm{Me}$ & Melakukan pendataan stok material. \\
\hline $\mathrm{Me}$ & Memeriksa keadaan setiap material dalam keadaan siap pakai atau tidak. \\
\hline $\mathrm{Me}$ & Membuat surat permintaan, pemusnahan, dan perbaikan material. \\
\hline $\mathrm{Me}$ & Mengkonfirmasikan kepada marketing tentang order produk dari material yang tidak terpakai selama 1 tahun. \\
\hline $\begin{array}{l}\mathrm{Me} \\
\operatorname{Inv}\end{array}$ & $\begin{array}{l}\text { Melakukan investigasi jika terjadi lonjakan permintaan kebutuhan tool pendukung dan melaporkan hasilnya kepada } \\
\text { Inventory Planner. }\end{array}$ \\
\hline \multicolumn{2}{|c|}{ C. KEWENANGAN \& HAK } \\
\hline $\mathrm{Me}$ & Memberikan keputusan untuk menerima material atau tidak berdasarkan kelengkapannya. \\
\hline $\mathrm{Me}$ & Mengajukan pengadaan tool pendukung kepada Inventory Planning dan Control. \\
\hline $\mathrm{Me}$ & Menagih kepada pihak peminjam tool untuk pengembalian tool. \\
\hline $\mathrm{Me}$ & Meminta informasi kendala pemenuhan tool dari dept. purchasing. \\
\hline $\mathrm{Me}$ & Menerima pelatihan/ training dari HRD sesuai dengan yang diajukan oleh PPIC Process. \\
\hline \multicolumn{2}{|l|}{ LAPORAN } \\
\hline Lap & Laporan penggunaan tool (3 Bulan) \\
\hline $\mathrm{Jad}$ & Jadwal kedatangan tool (3 Bulan) \\
\hline Lap & Laporan stok tool (3 Bulan) \\
\hline Lap & Laporan deadstock tool (3 Bulan) \\
\hline
\end{tabular}

\section{Usulan}

Saran yang akan diajukan bertujuan untuk membuat gudang material yang ada saat ini menjadi lebih baik. Usulan yang akan diberikan didasarkan dengan kebutuhan gudang material agar dapat berfungsi sebagai pengatur dan pengontrol material.

\section{Rancangan Job Description}

Gudang Material Penunjang haruslah ditangani oleh orang yang fokus hanya pada pengaturan dan persiapan material penunjang untuk produksi seperti staf gudang bahan baku yang fokus dalam penyediaan bahan baku. Staf Gudang Material Penunjang harus mempunyai job description yang jelas agar dapat berfungsi sebagaimana mestinya dalam pengoperasian gudang. Rancangan job description untuk staf Gudang Material Penunjang dapat dilihat pada Tabel 2.

\section{Rancangan Standard Operating Procedure Gudang Material Penunjang}

Ada 2 SOP yang dibuat untuk Gudang Material Penunjang yaitu SOP penerimaan, penyimpanan, dan pengeluaran material, dan SOP pemusnahan material. Pada SOP 
penerimaan, penyimpanan, dan pengeluaran material, dapat dilihat bahwa yang pertama dilakukan adalah staf Gudang Material Penunjang melihat jadwal induk produksi dari PPIC agar dapat mengetahui produksi untuk produk mana yang jalan duluan. Setelah cek jadwal, maka staf harus mengecek material pada gudang apakah material penunjangnya tersedia atau tidak.

Jika tidak tersedia atau kapasitas material habis, maka staf gudang akan melakukan pengadaan material mengikuti instruksi kerja penyediaan material yang bisa dilihat pada Tabel 3. Staf Gudang Material Penunjang selanjutnya menyiapkan material yang akan dipakai untuk produksi ketika material ada dan menunggu produksi mengambil material tersebut. Ketika produksi mau mengambil material, maka staf gudang harus mengikuti instruksi kerja pengeluaran dan pengembalian material yang bisa dilihat pada Tabel 4 .
Dalam SOP pemusnahan material hal yang dilakukan pertama kali adalah staf gudang mendata dahulu material apa saja yang sudah tidak pernah keluar atau terpakai dalam kurun waktu 1 tahun. Setelah selesai membuat list materialnya staf gudang akan mengajukannya ke divisi marketing. Hal ini dilakukan karena marketing yang lebih memahami dan bisa memutuskan persoalan pesanan dari customer. Dari data material yang diajukan, hanya material yang disetujui oleh marketing yang akan dibuat BAP (Berita Acara Pemusnahan) dan diajukan ke marketing, GM, dan HR-GA untuk mendapat persetujuan pemusnahan. Data material yang tidak disetujui, materialnya akan tetap disimpan dan akan diajukan kembali untuk pemusnahan jika tidak/ belum dipakai 6 bulan setelah pengajuan pertama.

Tabel 3. Instruksi Kerja Penyediaan Material

\begin{tabular}{clc}
\hline NO. & \multicolumn{1}{c}{ AKTIVITAS } & PENANGGUNG JAWAB \\
\hline 1. & Staf gudang mendapat/ melihat jadwal induk. & Staf gudang \\
\hline 2. & Staf gudang membaca peraturan penanganan material. & Staf gudang \\
\hline 3. & $\begin{array}{l}\text { Staf gudang mengecek material pada gudang. } \\
\text { Note }:\end{array}$ & Staf gudang \\
& $\begin{array}{l}\text { Staf gudang akan diinformasikan langsung oleh PPIC untuk membuat PO request material baru jika } \\
\text { merupakan Order Baru/ Repeat Order Baru. }\end{array}$ & \\
\hline 4. & $\begin{array}{l}\text { Jika kapasitas material kurang/ material tidak ada, maka staf gudang harus menginformasikan ke } \\
\text { staf PPIC dan membuat PO material ke R\&D. }\end{array}$ & Staf gudang \\
\hline 5. & Staf gudang meminta estimasi tanggal ketersediaan material kepada R\&D. & Staf gudang \\
\hline 6. & Staf gudang mengambil material dan melakukan serah terima dari R\&D. & Staf gudang \\
\hline 7. & Staf gudang meletakkan material di tempat dropship pada kantor gudang material penunjang. & Staf gudang \\
\hline 8. & $\begin{array}{l}\text { Staf gudang melakukan update data pada list/ tabel induk material. } \\
\text { Note }:\end{array}$ & Staf gudang \\
& $\begin{array}{l}\text { Material pada dropship tidak harus diletakkan pada rak material jika jeda waktu dengan mulai } \\
\text { produksi berdekatan }( \pm \text { hari). }\end{array}$ & Staf gudang \\
\hline 9 & $\begin{array}{l}\text { Staf gudang langsung menyiapkan material untuk produksi ketika kapasitas masih cukup pada } \\
\text { tempat dropship. }\end{array}$ & Staf gudang \\
\hline
\end{tabular}

Tabel 4. Instruksi Kerja Pengeluaran dan Pengembalian Material

\begin{tabular}{|c|c|c|}
\hline NO. & AKTIVITAS & PENANGGUNG JAWAB \\
\hline \multirow[t]{2}{*}{1.} & $\begin{array}{l}\text { Kasie produksi meminta material (tools) penunjang produksi kepada staf gudang material } \\
\text { penunjang. } \\
\text { Note : }\end{array}$ & Kasie Produksi \\
\hline & $\begin{array}{l}\text { Jika tool penunjang yang diminta tidak tersedia, staf wajib memberikan estimasi tanggal } \\
\text { ketersediaan tool penunjang. }\end{array}$ & \\
\hline 2. & $\begin{array}{l}\text { Staf gudang meminta kasie produksi untuk menunjukkan PO produksi sebagai bukti permintaan } \\
\text { material. }\end{array}$ & Staf gudang \\
\hline 3. & $\begin{array}{l}\text { Staf gudang mengkonfirmasi permintaan material dan memperlihatkan peraturan peminjaman } \\
\text { kepada kasie produksi. }\end{array}$ & Staf gudang \\
\hline 4. & $\begin{array}{l}\text { Setelah kasie produksi selesai membaca peraturan peminjaman material, staf gudang dan kasie } \\
\text { produksi bersama-sama memeriksa material penunjang yang telah disiapkan. }\end{array}$ & Staf gudang \& Kasie Produksi \\
\hline 5. & $\begin{array}{l}\text { Staf gudang meminta tanda tangan kasie produksi pada kartu stok sebagai tanda setuju material } \\
\text { telah sesuai dan membaca peraturan peminjaman. }\end{array}$ & Staf gudang \\
\hline 6. & Staf gudang melakukan serah terima material ke kasie produksi. & Staf gudang \\
\hline 7. & Staf gudang mencatat status material keluar pada list material. & Staf gudang \\
\hline 8. & $\begin{array}{l}\text { Ketika jadwal produksi suatu produk telah selesai, staf gudang mengingatkan pada kasie produksi } \\
\text { untuk mengembalikan material. }\end{array}$ & Staf gudang \\
\hline 9. & Kasie produksi mengembalikan material pada gudang. & Kasie Produksi \\
\hline 10. & $\begin{array}{l}\text { Staf gudang memeriksa kelengkapan material dan meminta tanda tangan kasie produksi pada kartu } \\
\text { stok sebagai bukti pengembalian material. }\end{array}$ & Staf gudang \\
\hline 11. & Staf gudang memeriksa keadaan material yang dikembalikan masih baik atau tidak. & Staf gudang \\
\hline 12. & $\begin{array}{l}\text { Staf gudang membuat berita acara pemusnahan jika material sudah tidak dapat dipakai dan } \\
\text { memisahkan material pada tempat khusus. }\end{array}$ & Staf gudang \\
\hline 13. & $\begin{array}{l}\text { Staf gudang memeriksa kapasitas material yang tersisa (untuk material yang mempunyai kapasitas } \\
\text { penggunaan). }\end{array}$ & Staf gudang \\
\hline 14. & $\begin{array}{l}\text { Staf gudang mengajukan pemusnahan material jika kapasitas yang tersisa terlalu sedikit untuk } \\
\text { produksi dan memisahkan material pada tempat khusus. }\end{array}$ & Staf gudang \\
\hline 15. & $\begin{array}{l}\text { Jika masih ada kapasitas, staf gudang meletakkan material kembali pada rak dan mencatat status } \\
\text { material. }\end{array}$ & Staf gudang \\
\hline
\end{tabular}


Tabel 5. Aturan bagi Staf

\begin{tabular}{ll}
\hline \multicolumn{1}{c}{ ATURAN/ KEWAJIBAN YANG BERLAKU BAGI STAF GUDANG MATERIAL PENUNJANG } \\
\hline 1. & Staf wajib memperlihatkan/ membacakan peraturan yang ada kepada peminjam. \\
\hline 2. & Staf wajib melihat PO dari peminjam sebelum memberikan material yang mau dipinjam. \\
\hline 3. & Staf wajib meminta tanda tangan peminjam pada kartu stok pada saat meminjam maupun mengembalikan. \\
\hline 4. & $\begin{array}{l}\text { Staf wajib memeriksa kelengkapan material yang diberikan (khususnya map besar yang berisi dieline, map approval, contoh cetakan, dan } \\
\text { plate). }\end{array}$ \\
\hline 5. & Staf berhak menolak pengembalian, jika material yang dikembalikan belum lengkap. \\
\hline 6. & Staf wajib membuat surat kehilangan material dan ditanda tangan oleh peminjam jika menghilangkan material. \\
\hline 7. & Staf wajib memeriksa kembali kelengkapan material yang telah dikembalikan peminjam. \\
\hline 8. & Staf wajib menjaga keselamatan dan keamanan dirinya dalam bekerja. \\
\hline 9. & Kecelakaan kerja yang disebabkan staf karena melanggar aturan/ SOP yang berlaku menjadi tanggung jawab staf sendiri. \\
\hline 10. & Staf wajib melaporkan segala bentuk kerusakan yang terjadi pada alat, kelengkapan, dan material. \\
\hline 11. & $\begin{array}{l}\text { Aturan ini berlaku selama staf menjalankan tugasnya sebagai pengelola Gudang Material Penunjang dan tidak bertentangan dengan tugas } \\
\text { 12. }\end{array}$ \\
\hline
\end{tabular}

Tabel 6. Aturan bagi Peminjam

ATURAN / KEWAJIBAN YANG BERLAKU BAGI PEMINJAM

\begin{tabular}{ll}
\hline 1. & Adanya PO yang wajib dibawa dan diperlihatkan sebagai syarat melakukan peminjaman. \\
\hline 2. & $\begin{array}{l}\text { Material yang dipinjamkan akan dipastikan dahulu kelengkapannya oleh staf dan peminjam, peminjam menandatangani kartu stok ketika } \\
\text { meminjam material dan sebagai tanda setuju bahwa material yang dipinjamkan telah sesuai. }\end{array}$ \\
\hline 3. & $\begin{array}{l}\text { Material harus dikembalikan lengkap sesuai dengan yang telah diberikan oleh staf, jika tidak lengkap maka material tidak akan diterima } \\
\text { oleh staf (kecuali kehilangan). }\end{array}$ \\
\hline 4. & Peminjam harus melaporkan keadaan material yang dipinjamnya jika ada kerusakan pada material yang dipinjamnya. \\
\hline 5. & $\begin{array}{l}\text { Peminjam harus bertanggung jawab terhadap material yang dipinjamnya selama di luar (tidak boleh hilang), bukan berarti tidak boleh } \\
\text { dipinjamkan kepada departemen lain. }\end{array}$ \\
\hline 6. & Peminjam dapat menyerahkan tanggung jawab material yang dipinjam pada orang lain yang akan mengembalikan material tersebut. \\
\hline 7. & Aturan di atas harus dibaca terlebih dahulu oleh peminjam sebelum melakukan peminjaman material. \\
\hline 8. & Menandatangani kartu stok juga menandakan bahwa peraturan telah dibaca dengan seksama. \\
\hline 9. & Peraturan dapat dicetak dan diberikan kepada peminjam jika dibutuhkan. \\
\hline 10. & Segala bentuk kesalahan yang disebabkan kelalaian dan pelanggaran peraturan oleh peminjam menjadi tanggung jawab peminjam. \\
\hline
\end{tabular}

Tabel 7. Aturan Penanganan Material

\section{ATURAN PENANGANAN MATERIAL}

1. Material baru, material selesai pakai, atau material yang disiapkan untuk pemin-jaman harus diletakkan di tempat dropship sebelum

1. diletakkan/dikeluarkan.

2. Material yang berada pada tempat dropship harus sudah didata dan dipindahkan ke gudang material maksimal 4 jam setelah material diberikan.

3. Pelabelan nama pada material ditulis selengkap-lengkapnya sesuai dengan PO.

4. Pemindahan material harus dilakukan dengan hati-hati terutama untuk material yang berat, staf harus selalu memperhatikan keselamatan kerja

5. Staf harus menggunakan alat bantu tangga untuk material yang diletakkan pada rak bertingkat.

6. Staf meletakkan material secara urut berdasarkan kode barang.

7. Dieline/diecut berupa kertas akan disiapkan oleh staf selaku penyedia material penunjang, dieline/diecut kertas akan diganti dengan yang baru ketika

7. proses produksi berikutnya akan berjalan (staf harus membuang yang lama dan tidak memerlukan BAP).

8. Material yang disimpan pada gudang haruslah material yang belum melewati masa pakai, belum rusak, dan masih ada kapasitas produksi.

9. Staf dilarang keras menyimpan material dengan kondisi rusak, melewati masa pakai, dan kapasitas terlalu sedikit untuk produksi tanpa alasan yang

9. kuat (harus segera diajukan ke marketting dan RnD untuk pembaruan atau pemusnahan).

10. Atasan (PPIC) akan menginspeksi Gudang Material Penunjang setiap 3 bulan sekali (dapat berubah sesuai kebutuhan) pada saat stok opname

10. berlangsung agar tetap terkontrol dan berjalan sesuai fungsinya.

11. Segala bentuk pelanggaran peraturan yang dilakukan akan dikenakan sanksi sesuai yang berlaku.

\section{Rancangan Aturan dan Wewenang Gudang Material Penunjang}

Aturan dan wewenang yang dibuat lebih bertujuan kearah penerapan proses agar menjadi lebih maksimal dan terkontrol. Aturan dan wewenang yang berlaku bagi staf, peminjam (produksi), maupun material. Aturan yang berlaku bagi staf dapat dilihat pada Tabel 5. Aturan yang berlaku bagi peminjam dapat dilihat pada Tabel 6 dan aturan yang berlaku untuk penanganan material dapat dilihat pada Tabel 7 .

\section{Perancangan Tata Letak}

Layout untuk Gudang Material Penunjang akan terbagi 2 yaitu gudang material dan kantor Gudang Material Penunjang. Layout yang digunakan sebagai gudang material adalah gudang pisau untuk menyimpan pisau plong, map besar, dan dus polymer. Layout untuk kantor Gudang Material Penunjang adalah ruangan untuk materialmaterial lain yang tidak masuk dalam gudang beserta kantor staf. Layout untuk kantor Gudang Material Penunjang dapat dilihat pada Gambar 3 dan gudang material pada Gambar 4. Material pada gudang material akan diletakkan pada rak yang sebelumnya digunakan pisau plong dan akan dibagi tempat peletakannya. Rak yang digunakan adalah rak tumpuk 3 dengan baris ke samping sebanyak 22. Kapasitas rak dan pembagiannya dapat dilihat pada Tabel 8 . 


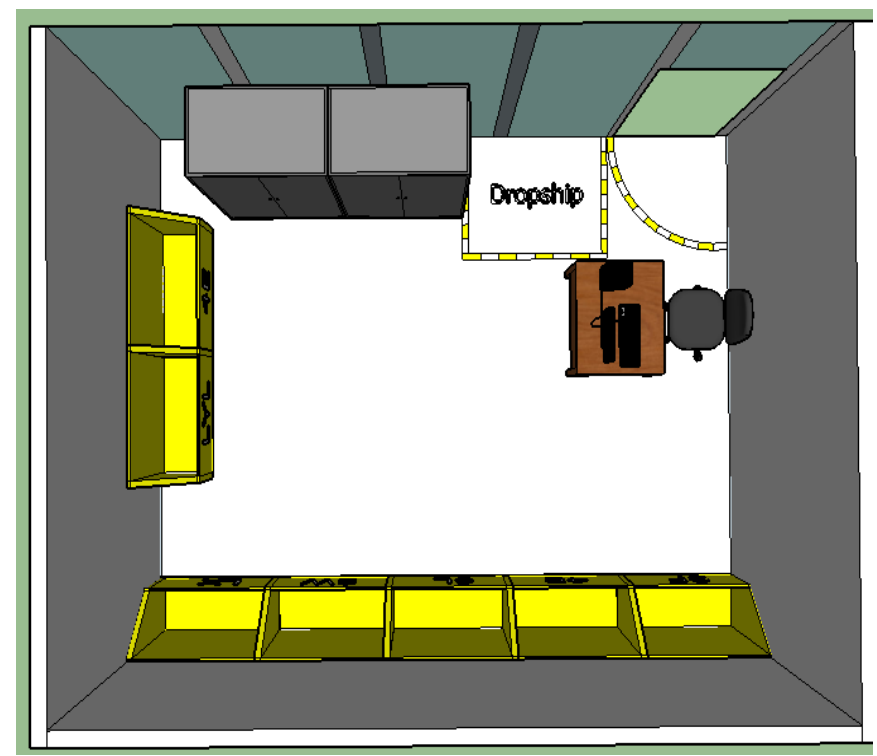

Gambar 3. Kantor Gudang Material Penunjang (Tampak Atas)

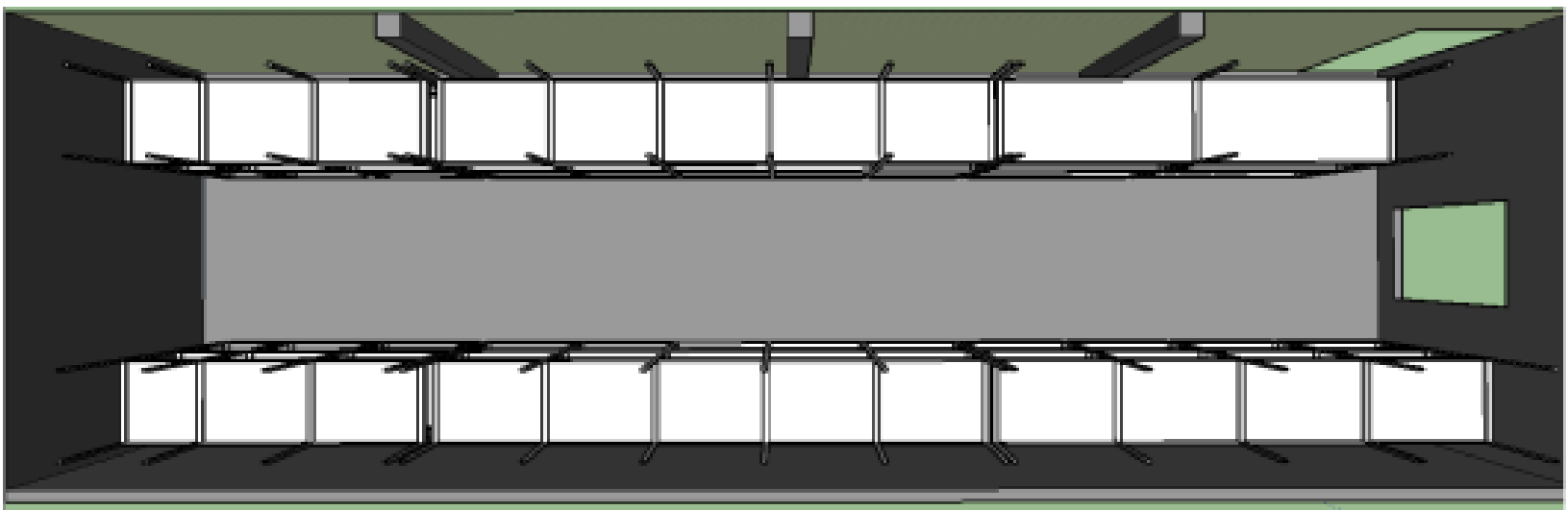

Gambar 4. Gudang Material (Tampak Atas)

Tabel 8. Kapasitas Rak

\begin{tabular}{|c|c|c|c|c|c|c|c|c|c|}
\hline \multicolumn{5}{|c|}{ KAPASITAS RAK KANAN } & \multicolumn{5}{|c|}{ KAPASITAS RAK KIRI } \\
\hline \multirow[b]{2}{*}{ RAK } & \multirow{2}{*}{$\begin{array}{c}\text { UKURAN } \\
(\mathbf{c m})\end{array}$} & \multicolumn{3}{|c|}{ KOLOM } & \multirow[b]{2}{*}{ RAK } & \multirow{2}{*}{$\begin{array}{c}\text { UKURAN } \\
(\mathbf{c m})\end{array}$} & \multicolumn{3}{|c|}{ KOLOM } \\
\hline & & $\mathbf{1}$ & 2 & 3 & & & 1 & 2 & 3 \\
\hline A & 110 & 36 & 36 & 55 & $\mathrm{M}$ & 66 & 13 & 13 & 33 \\
\hline B & 113 & 37 & 37 & 56 & $\mathrm{~N}$ & 99 & 19 & 19 & 49 \\
\hline $\mathrm{C}$ & 112 & 37 & 37 & 56 & $\mathrm{O}$ & 99 & 19 & 19 & 49 \\
\hline $\mathrm{D}$ & 110 & 36 & 36 & 55 & $P$ & 99 & 33 & 33 & 49 \\
\hline $\mathrm{E}$ & 99 & 33 & 33 & 49 & $\mathrm{Q}$ & 99 & 33 & 33 & 49 \\
\hline $\mathrm{F}$ & 99 & 33 & 33 & 49 & $\mathrm{R}$ & 99 & 33 & 33 & 49 \\
\hline $\mathrm{G}$ & 99 & 33 & 33 & 49 & S & 99 & 33 & 33 & 49 \\
\hline $\mathrm{H}$ & 99 & 33 & 33 & 49 & $\mathrm{~T}$ & 99 & 33 & 33 & 49 \\
\hline I & 99 & 33 & 33 & 49 & $\mathrm{U}$ & 180 & 60 & 36 & 90 \\
\hline $\mathrm{J}$ & 99 & 19 & 19 & 49 & V (TEMPAT KHUSUS) & 180 & 60 & 36 & 90 \\
\hline $\mathrm{K}$ & 99 & 19 & 19 & 49 & & & & & \\
\hline $\mathrm{L}$ & 68 & 13 & 13 & 34 & & & & & \\
\hline
\end{tabular}

\begin{tabular}{lc}
\multicolumn{2}{c}{ TOTAL KAPASITAS } \\
\hline DUS POLYMER & 204 \\
PISAU PLONG & 952 \\
MAP BESAR & 975 \\
\hline
\end{tabular}

Pada Tabel 8 dapat dilihat bahwa pembagian rak dan kolom untuk material pisau plong, map besar, dan polymer telah dilakukan. Pisau plong akan diletakkan pada kolom paling bawah dan kolom tengah (kolom 1 \& 2). Hal ini dilakukan lantaran pisau plong merupakan material terberat daripada material yang lainnya $( \pm 20 \mathrm{Kg}$ ). Tinggi setiap kolom pada rak sebesar $84 \mathrm{~cm}$ yang membuat map besar tidak dapat masuk (tinggi map besar $87 \mathrm{~cm}$ ). Sedangkan dus polymer tingginya hanya berkisar $83 \mathrm{~cm}$ dan bisa masuk pada kolom manapun.

\section{Pelabelan dan Penyusunan Material}

Pelabelan nama material pada Gudang Material Penunjang akan dibuat berdasarkan nama produk dan kode barang produk tersebut. Hal ini dilakukan agar memudahkan mencari material, serta dapat mencocokkan apakah material yang dicari sudah sesuai dengan kode barangnya atau tidak. Contoh pelabelan nama material pada fisik material :

- IN TONGJIE LUBANG - T037-0032

- IN JASMINE TEA - T037-0002

- GB NAGOYA - T039-0010 
Penyusunan material akan menggunakan penggabungan antara metode floating location system dan fixed location system yang dirasa lebih memungkinkan dan cocok untuk diterapkan disesuaikan dengan kondisi perusahaan. Rak material akan diberikan abjad, mulai dari A-V seperti pada Tabel 2, kolom paling bawah akan mendapatkan tambahan angka 1, kolom tengah akan mendapat tambahan angka 2, dan kolom paling atas akan mendapat tambahan angka 3 . Satu rak A akan terdiri dari kolom A1, A2, dan A3, begitu juga dengan rak lainnya. A1 berarti rak A untuk kolom paling bawah, A2 berarti rak A untuk kolom tengah, dan A3 berarti rak A untuk kolom paling atas. Penataan material pada rak diurutkan dari kode barangnya agar memudahkan pencarian material. Penataan selalu dimulai dari rak A1, kemudian ke A2, dan baru ke B1 (pengaturan sesuai materialnya, jika map besar, maka dimulai dari rak A3). Setelah meletakkan material tersebut, staf Gudang Material Penunjang akan meng-update pada tabel induk material untuk posisi material berada pada kolom mana. Tabel induk material dapat dilihat pada Tabel 9.

Karena merupakan penggabungan dua metode dari floating location system yang memakai sistem pengalokasian dan fixed location system yang menggunakan metode pengurutan berdasarkan kode barangnya, maka sistem penataan ini juga mempunyai kelemahan. Kelemahan pada sistem ini adalah ketika ada pertambahan material baru dan tidak ada tempat kosong sesuai dengan kode barangnya, maka harus menggeser material yang sudah tertata sebelumnya. Untuk mengatasi kelemahan ini, maka material baru akan diletakkan dahulu pada rak ekstra (rak U) sampai ada material yang keluar dan memberikan space kosong yang dirasa cukup untuk menggeser material atau sampai pada saatnya stok opname nantinya (3 bulan sekali). Pada saat stok opname, staf Gudang Material Penunjang dapat mengatur kembali raknya bersamaan dengan mencocokkan data pada tabel materialnya. Kolom rak bagian kiri yang paling dekat dengan pintu (rak V) akan digunakan sebagai rak khusus material afkir (material yang rusak, sudah habis kapasitasnya, atau yang mau dimusnahkan). Seperti yang dapat dilihat pada Tabel 8 sebelumnya, untuk kolom rak paling atas (semua kolom 3, tidak termasuk rak $\mathrm{U}$ dan V) dipakai untuk penempatan map besar yang juga akan disusun dan di update seperti pisau plong. 2 kolom keatas dan 3 kolom kesamping paling belakang (tepatnya kolom 1 dan $2 \operatorname{rak} \mathrm{J}, \mathrm{K}, \mathrm{L}, \mathrm{M}, \mathrm{N}$, O) pada rak akan digunakan untuk meletakkan polymer yang juga disusun dan di update seperti pisau plong.

Tabel 9. Tabel Induk Material

\begin{tabular}{|c|c|c|c|c|c|c|c|c|c|c|}
\hline NO & $\begin{array}{c}\text { KODE } \\
\text { BARANG }\end{array}$ & NAMA JOB & $\begin{array}{c}\text { JENIS } \\
\text { MATERIAL }\end{array}$ & ISI & $\begin{array}{l}\text { MASA } \\
\text { HIDUP }\end{array}$ & $\begin{array}{l}\text { BATAS } \\
\text { PAKAI }\end{array}$ & $\begin{array}{c}\text { SISA } \\
\text { KAPASITAS }\end{array}$ & KONDISI & $\begin{array}{l}\text { TERAKHIR } \\
\text { KELUAR }\end{array}$ & LOKASI \\
\hline 1 & $\begin{array}{c}\text { G029- } \\
0142\end{array}$ & $\begin{array}{l}\text { IN TBB } 15 \text { BKS } \\
\text { RD4RB1RL1 }\end{array}$ & $\begin{array}{l}\text { MAP } \\
\text { BESAR }\end{array}$ & $\begin{array}{l}\text { DIELINE, } \\
\text { CONTOH } \\
\text { CETAKAN, } \\
\text { MAP } \\
\text { APPROVAL }\end{array}$ & $\begin{array}{l}20-07- \\
17\end{array}$ & & & B & $20-08-16$ & KELUAR \\
\hline 2 & $\begin{array}{l}\text { G029- } \\
0142\end{array}$ & $\begin{array}{l}\text { IN TBB 15 BKS } \\
\text { RD4RB1RL1 }\end{array}$ & $\begin{array}{l}\text { PISAU } \\
\text { PLONG }\end{array}$ & & & 250,000 & 100,000 & B & 09-08-16 & A2 \\
\hline 3 & $\begin{array}{c}\text { G029- } \\
0142 \\
\end{array}$ & $\begin{array}{l}\text { IN TBB 15 BKS } \\
\text { RD4RB1RL1 }\end{array}$ & PLATE & & & 70,000 & 10,000 & B & 07-07-16 & LYL \\
\hline 4 & $\begin{array}{c}\mathrm{G} 029- \\
0142\end{array}$ & $\begin{array}{l}\text { IN TBB } 15 \text { BKS } \\
\text { RD4RB1RL1 }\end{array}$ & POLYMER & & & & & $\mathrm{R}$ & $15-07-16$ & V2 \\
\hline 5 & $\begin{array}{c}\text { G029- } \\
0200\end{array}$ & $\begin{array}{l}\text { IN TBB } 30 \text { ERECTOR } \\
\text { RP1 }\end{array}$ & $\begin{array}{l}\text { MAP } \\
\text { BESAR }\end{array}$ & $\begin{array}{l}\text { DIELINE, } \\
\text { CONTOH } \\
\text { CETAKAN, } \\
\text { MAP } \\
\text { APPROVAL }\end{array}$ & $\begin{array}{l}13-03- \\
17\end{array}$ & & & B & $13-04-16$ & F3 \\
\hline 6 & $\begin{array}{c}\text { G029- } \\
0200\end{array}$ & $\begin{array}{l}\text { IN TBB } 30 \text { ERECTOR } \\
\text { RP1 }\end{array}$ & $\begin{array}{l}\text { PISAU } \\
\text { PLONG }\end{array}$ & & & 250,000 & 100,000 & B & $12-05-16$ & $\mathrm{~B} 2$ \\
\hline 7 & $\begin{array}{c}\text { G029- } \\
0200\end{array}$ & $\begin{array}{l}\text { IN TBB } 30 \text { ERECTOR } \\
\text { RP1 }\end{array}$ & PLATE & & & 70,000 & 5,000 & B & $13-06-16$ & $6 \mathrm{~L}$ \\
\hline 8 & $\begin{array}{c}\text { G029- } \\
0200\end{array}$ & $\begin{array}{l}\text { IN TBB } 30 \text { ERECTOR } \\
\text { RP1 }\end{array}$ & HOTSTAMP & & & & & $\mathrm{R}$ & $20-08-16$ & EMB3 \\
\hline 9 & $\begin{array}{c}\text { M027- } \\
1681\end{array}$ & $\begin{array}{l}\text { GB INDOMIE MKGS } \\
\text { SQN ARAB }\end{array}$ & $\begin{array}{l}\text { MAP } \\
\text { BESAR }\end{array}$ & $\begin{array}{l}\text { DIELINEa, } \\
\text { CONTOH } \\
\text { CETAKAN, } \\
\text { MAP } \\
\text { APPROVAL }\end{array}$ & $\begin{array}{l}20-07- \\
17\end{array}$ & & & B & $20-08-16$ & G3 \\
\hline 10 & $\begin{array}{c}\text { M027- } \\
1681\end{array}$ & $\begin{array}{l}\text { GB INDOMIE MKGS } \\
\text { SQN ARAB }\end{array}$ & $\begin{array}{l}\text { PISAU } \\
\text { PLONG }\end{array}$ & & & 250,000 & 50,000 & B & 09-08-16 & $\mathrm{C} 2$ \\
\hline 11 & $\begin{array}{c}\text { M027- } \\
1681\end{array}$ & $\begin{array}{l}\text { GB INDOMIE MKGS } \\
\text { SQN ARAB }\end{array}$ & PLATE & & & 70,000 & 5,000 & B & $07-07-16$ & $4 \mathrm{E}$ \\
\hline 12 & $\begin{array}{c}\text { M124- } \\
0001\end{array}$ & $\begin{array}{l}\text { IN CHOKI-CHOKI } \\
\text { CHOCO CASHEW } \\
20 X 11 \mathrm{G}\end{array}$ & $\begin{array}{l}\text { MAP } \\
\text { BESAR }\end{array}$ & $\begin{array}{l}\text { DIELINE, } \\
\text { CONTOH } \\
\text { CETAKAN, } \\
\text { MAP } \\
\text { APPROVAL }\end{array}$ & $\begin{array}{l}15-08- \\
17\end{array}$ & & & B & $15-07-16$ & F3 \\
\hline 13 & $\begin{array}{c}\text { M124- } \\
0001\end{array}$ & $\begin{array}{l}\text { IN CHOKI-CHOKI } \\
\text { CHOCO CASHEW } \\
20 \mathrm{X} 11 \mathrm{G}\end{array}$ & $\begin{array}{l}\text { PISAU } \\
\text { PLONG }\end{array}$ & & & $1,000,000$ & 100,000 & B & $13-04-16$ & B2 \\
\hline 14 & $\begin{array}{c}\text { M124- } \\
0001\end{array}$ & $\begin{array}{l}\text { IN CHOKI-CHOKI } \\
\text { CHOCO CASHEW } \\
20 X 11 \mathrm{G}\end{array}$ & PLATE & & & 70,000 & 100,000 & B & $12-05-16$ & $4 \mathrm{E}$ \\
\hline 15 & $\begin{array}{c}\text { M124- } \\
0001\end{array}$ & $\begin{array}{l}\text { IN CHOKI-CHOKI } \\
\text { CHOCO CASHEW } \\
20 X 11 \mathrm{G}\end{array}$ & HOTSTAMP & & & & & B & $13-06-16$ & EMB3 \\
\hline
\end{tabular}


Tabel 10. Kartu Stok

KARTU STOK

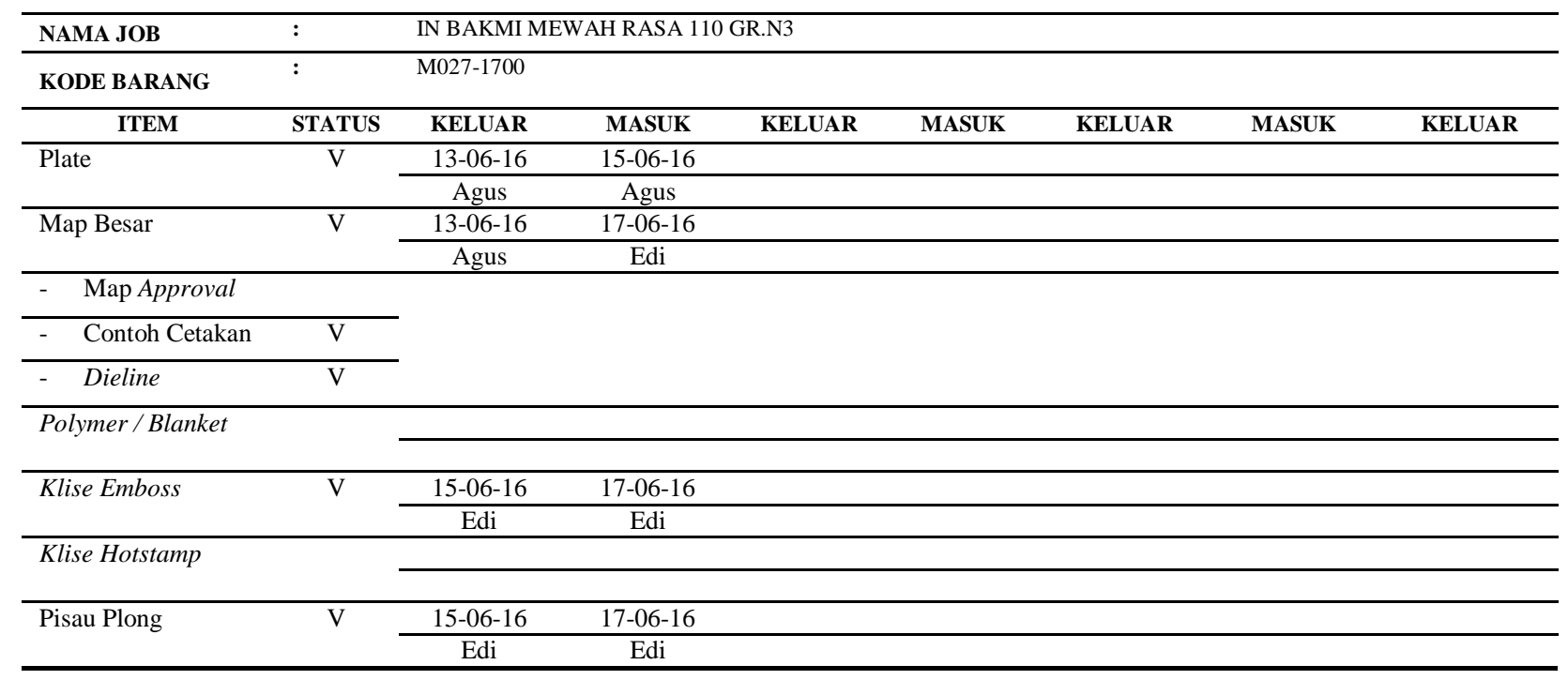

\section{Rancangan Operasional Sistem Manajemen Gudang}

Rancangan ini dibuat untuk mengontrol Gudang

Material Penunjang agar masalah yang sama tidak terjadi kembali. Pembuatan kartu stok dilakukan untuk mengetahui material apa saja yang lagi keluar dari gudang. Selain itu, pembuatan kartu stok sebagai kontrol terhadap posisi material agar material tidak diletakkan sembarangan pada lantai produksi. Kartu stok juga berfungsi sebagai pencocokan data material dengan stok fisik ketika dilakukannya stok opname. Kartu stok dibuat untuk setiap job yang jalan pada PT XYZ dan berisi list kelengkapan material yang digunakan untuk menjalankan produksi produk tersebut. Kartu stok dapat dilihat pada Tabel 10.

Tidak semua produk memakai semua material penunjang. Material yang dipakai produk tersebut akan dicentang pada kolom status ketika material tersebut ada. Untuk dieline biasanya hanya ada 1 dan dapat dipakai untuk proses produksi dari offset sampai finishing 1. Kolom yang berisi nama dibawah tanggal pada kartu stok dipakai untuk tanda tangan peminjam. Seperti yang dilihat pada Tabel 10, material map besar di pinjam oleh Agus (Kepala regu offset) dan dikembalikan oleh Edi (Kepala sie finishing 1). Map besar diserahkan ke bagian finishing 1 dan tidak dikembalikan pada Gudang Material Penunjang dahulu, hal ini diperbolehkan dengan aturan orang terakhir yang memakai akan mengembalikan. Jika produksi tidak mengembalikan material sampai waktu pada PO sudah selesai, staf Gudang Material Penunjang wajib menagih material tersebut pada produksi.

Penelitian ini berkontribusi dalam menyatukan penggunaan fixed dan floating location system. Berdasarkan pemilihan location system yang sesuai dengan kondisi perusahaan, sangatlah memungkinkan jika menggabungkan kedua tipe location system yang sebelumnya telah dijelaskan. Hal ini dikarenakan berguna untuk menggolongkan barang berdasarkan kode dan alokasi sistem secara bersamaan.

\section{Kesimpulan}

Berdasarkan hasil analisa dan pembahasan, terdapat 5 usulan yang dapat digunakan untuk mengatasi permasalahan yang ada. Usulan tersebut adalah sebagai berikut:

- Rancangan job description staf bertujuan membuat staf fokus pada pekerjaannya dan lebih mampu mengontrol gudang material.

- Rancangan SOP yang dibuat diharapkan mampu mengontrol dan menilai kinerja staf.

- Rancangan peraturan yang dibuat bertujuan agar Gudang Material Penunjang berjalan sebagaimana mestinya tanpa ada halangan berarti dari pihak-pihak lain.

- Pelabelan dan penyusunan material didesain sedemikian rupa agar menyelesaikan persoalan pencarian material yang susah.

- Rancangan operasional Gudang Material Penunjang dilakukan agar dapat mengontrol gudang dan material didalamnya agar tidak terjadi hal yang tidak diinginkan seperti kehilangan material dan ada pertanggung jawaban yang jelas.

Dengan adanya tabel induk material sebagai pengontrol material dan kartu stok sebagai operasional gudang, diharapkan permasalahan pada gudang material dapat teratasi dan tidak terjadi kembali.

\section{Daftar Pustaka}

Richards, G. (2011). Warehouse Management: A Complete Guide to Improving Efficiency and Minimizing Costs In the Modern Warehouse. London: Kogan Page.

Arnold, J. R. Tony. (2008). Introduction to Material Management, (6th ed). New Jersey: Pearson Education, Inc.

Tompkins, J.A., and Smith, J.D. (1998). The Wrehouse Management Book, (2nd ed). North Carolina: Tompkins Press.

Rahardjo, B. dan Rahardjo, J., Peningkatan Yield Departemen XYZ pada PT X, Jurnal Titra, 1(2), 2013, pp. 199206. 
Hapsari, et.al., Perbaikan Tata Letak Gudang Peralatan Rumah Tangga di Surabaya, Prosiding Seminar Nasional Industrial Service, 2011.

Irawan, A., Analisa Discrepancy pada Perusahaan Jasa Manajemen Warehouse di PT. Cipta Krida Bahari Samarinda, Ekonomia, 3(3), 2014, pp. 269-278.

Leopatria, M. dan Palit, H.C., Perancangan Sistem Manajemen Gudang Tepung di PT X, Jurnal Titra, 1(2), 2013, pp. 49-56. 